\title{
Interaction of removal Ethidium Bromide with Carbon Nanotube: Equilibrium and Isotherm studies
}

\author{
Omid Moradi ${ }^{*}$, Mehdi Norouzi ${ }^{2}$, Ali Fakhri ${ }^{1}$ and Kazem Naddafi ${ }^{3}$
}

\begin{abstract}
Drinking water resources may be contaminated with Ethidium Bromide (EtBr) which is commonly used in molecular biology laboratories for DNA identification in electrophoresis. Carbon nanotubes are expected to play an important role in sensing, pollution treatment and separation techniques. In this study adsorption of Ethidium Bromide on single-walled carbon nanotubes (SWCNTs) and carboxylate group functionalized single-walled carbon nanotube (SWCNT-COOH) surfaces have been investigated by UV-vis spectrophotometer. The effect of contact time, initial concentration and temperature were investigated. The adsorbents exhibits high efficiency for EtBr adsorption and equilibrium can be achieved in 6 and 3 min for SWCNTs and SWCNT-COOH, respectively. The effect of temperature on adsorption of $\mathrm{EtBr}$ by toward adsorbents shows the process in this research has been endothermic. The results showed that the equilibrium data were well described by the Langmuir isotherm model, with a maximum adsorption capacity of 0.770 and $0.830 \mathrm{mg} / \mathrm{g}$ for SWCNTs and SWCNT-COOH, respectively. The adsorption of $\mathrm{EtBr}$ on SWCNT-COOH is more than SWCNTs surfaces. A comparison of kinetic models was evaluated for the pseudo first-order, pseudo second-order models. Pseudo second-order was found to agree well with the experimental data.
\end{abstract}

Keywords: Adsorption, Ethidium bromide, Single-walled carbon nanotube, Isotherm

\section{Introduction}

The contamination of drinking water with Non-radioactive materials such as Ethiduim bromide (EtBr) has become one of the most serious problems in water environment, especially in urban areas [1-3]. Ethidium bromide (3,8diamino-6-phenyl-5-ethylphenanthridinium bromide, EtBr;), a powerful mutagenic [4], is an intercalating agent which resembles a DNA base pair. Due to its unique structure, it can easily intercalate into DNA strand. Therefore, it is commonly used as nucleic acid fluorescent tag in various techniques of the life science field. EtBr is a potent mutagen for which the Environmental Health \& Safety advises a detoxification protocol [5], since earlier recommended oxidation by household bleach was recognized to lead to possible byproducts that could be more hazardous than the EtBr itself [6]. Taking the adsorption of dyes and

\footnotetext{
*Correspondence: moradi.omid@gmail.com

'Department of Chemistry, Shahre-Qods Branch, Islamic Azad University, Tehran, Iran

Full list of author information is available at the end of the article
}

organic pollutant, the usability of various natural and synthetic adsorbents have been studied, such as banana peel [7], orange peel [7], calcined layered double hydroxides [8], hypercrosslinked polymeric adsorbent [9], pinecone derived activated carbon [10]. Usually, the effectiveness of any adsorption process largely depends on the physicochemical properties of the adsorbent used. Since the discovery by Iijima [11], carbon nanotubes (CNTs) have attracted great attention in multidisciplinary areas due to their unique hollow tube structure and their many outstanding mechanical, electronic and optical properties [12]. In particular, carbon nanotubes (both multi-walled (MWCNT) and single walled (SWCNT)) are promising materials for several applications such as high performance composites [13-15], components in water filters [16,17], environmental sensors $[18,19]$, building blocks for electronic nanodevices [20], drug delivers [21], among others. CNTs are also considered to be extremely good adsorbents and successfully remove many kinds of organic and inorganic pollutants such as pentachlorophenol [22], 
benzene, toluene, ethylbenzene and p-xylene [23], o-xylene and p-xylene [24] and heavy metal ions such as U(VI) [25], $\mathrm{Cr}(\mathrm{VI})$ [26], $\mathrm{Zn}$ (II) [27], $\mathrm{Cu}(\mathrm{II})$ [28], $\mathrm{Pb}(\mathrm{II})$ [29], $\mathrm{Hg}$ (II) [30] and $\mathrm{Cd}(\mathrm{II})[31,32]$ from water. Activation of CNTs plays an important role in enhancing maximum adsorption capacity. Activation causes modification in the morphology and functional groups surfaces and causes removal of amorphous carbon. The objective of this study was to investigate the possible use of single walled carbon nanotubes as an alternative adsorbent material for the removal of $\mathrm{EtBr}$ from drinking water. Adsorption isotherms and kinetics parameters were also calculated and discussed. The dynamic behavior of adsorption was investigated on the effect of initial EtBr concentration, contact times and temperature of the solution.

\section{Material and methods}

SWCNTs and SWCNT-COOH (Armchair $(6,6)$, Young's Modulus (0.94 T TPa), Tensile strength (GPa126.2 T), purity > 95\%; diameter $1-2 \mathrm{~nm}$; length, 5-30 nm; surface area, $\sim 400 \mathrm{~m}^{2} / \mathrm{g}$; and manufacturing method purchased from NanoAmor Nanostructured \& Amorphous Materials, Inc. (USA) and catalytic chemical vapor deposition (CVD)) were prepared from DC-PECVD (Model: SI-PE80) Toseye Hesgarsazan Asia Co. Doubly distilled water was used and all adsorbents were washed before using. A scanning electron microscope (SEM) (JEOL JSM-5600 Digital Scanning Electron Microscope) was used to characterize the SWCNT-COOH and SWCNTs for morphological information. Ethidium bromide (molecular Weight: 394.35; molecular Formula: $\mathrm{C}_{21} \mathrm{H}_{20} \mathrm{BrN}_{3}$ ) was supplied by Merck, Germany (maximum purity available, $\geq 95 \%$ ). All solutions were prepared with deviations of less than $\pm 0.1 \%$ from the desired concentrations.

\section{Adsorption experiments}

The determination of ethiduim bromide concentration was performed using Lambda-EZ150UV/Vis Spectrophotometer at a wavelength of $274 \mathrm{~nm}$. The blank used in the experiment was distilled water without any EtBr. Batch adsorption experiments were performed in glass bottles with EtBr solution ( $1 \mathrm{~L}$ ) of the prescribed concentration ranging from 10 to $40 \mathrm{mg} / \mathrm{L}$ and $20 \mathrm{mg}$ of SWCNTs or SWCNT-COOH was added to each bottle. The amount of SWCNTs or SWCNT-COOH was fixed in all experimental steps. All experiments were conducted by mixing $20 \mathrm{~mL}$ of aqueous solutions with $0.02 \mathrm{~g}$ of the adsorbent solution composed of SWCNTs with EtBr, solution No. 1 was called and solution composed of SWCNTCOOH with EtBr, No. 2 was called. Then, the suspension 1 and 2 were centrifuged at $5000 \mathrm{rpm}$ for $5 \mathrm{~min}$ and $2 \mathrm{~min}$, respectively. The amount of the EtBr adsorbed onto the adsorbent was determined by the difference between the initial and remaining concentration of EtBr solution. The adsorption capacity of EtBr on adsorbent was calculated using the following equation [33]:

$$
\mathrm{q}_{\mathrm{e}}=\frac{\left(C_{i}-C_{t}\right) V}{W}
$$

where $C_{i}$ is the initial EtBr concentration and $C_{t}$ is the EtBr concentration $(\mathrm{mg} / \mathrm{L})$ at any time, $\mathrm{V}$ is the volume of solution (L) and $\mathrm{W}$ is the mass of the adsorbents $(\mathrm{g})$. The data analysis was carried out using correlation analysis employing least square method and the average relative error (ARE) is calculated using the following equation [33]:

$$
\operatorname{ARE}(\%)=\frac{100}{\mathrm{n}} \sum_{i}^{n}\left|\frac{q_{i}, \mathrm{cal}-q_{i}, \exp }{q_{i}, \exp }\right|
$$

where $\mathrm{N}$ is the number of data points. Each experiment was conducted in triplicate under identical conditions to confirm the results, and was found reproducible (experimental error within 3\%).

\section{Equilibrium}

To optimize the design of an adsorption system for the adsorption, it is important to establish the most appropriate correlation for the equilibrium curves. Various isotherm equations have been used to describe the equilibrium nature of adsorption. Some of these isotherms are Langmuir and Freundlich. One of the most common isotherm models which are widely used is the Langmuir model. It is observed that the Langmuir isotherms can be linearized to at least four different types. The Langmuir isotherm model can be expressed as:

$$
q_{e}=\frac{1}{(1+K C e)}
$$

where $\mathrm{Q}_{\mathrm{m}}(\mathrm{mg} / \mathrm{g})$ and $\mathrm{K}(\mathrm{L} / \mathrm{mg})$ are Langmuir constants related to adsorption capacity and energy of adsorption,

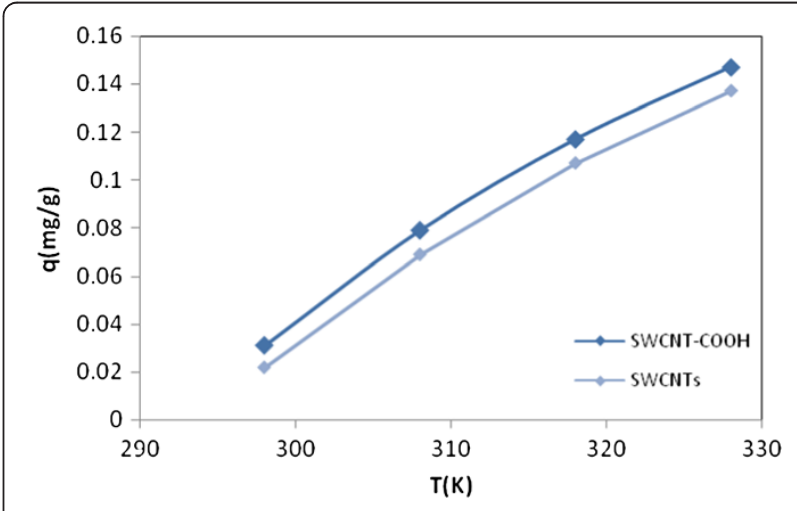

Figure 1 Effect of temperature on the adsorption of $\mathrm{EtBr}$ with SWCNTs and SWCNT-COOH, initial concentration, $20 \mathrm{ml}, 30 \mathrm{mg} / \mathrm{L}$; adsorbent dosage, $20 \mathrm{mg}$. 

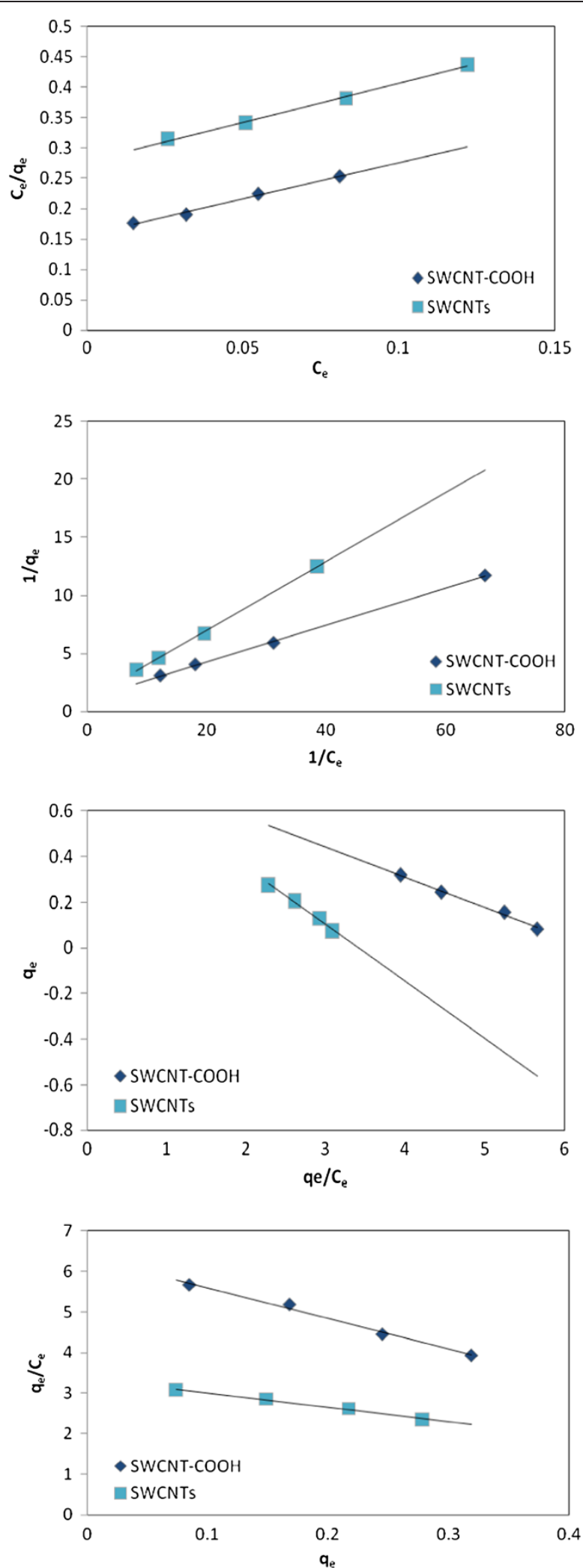

Figure 2 Langmuir isotherm of EtBr on SWCNTs and SWCNT-COOH; Type $1\left(C_{\mathrm{e}} / \mathrm{q}_{\mathrm{e}} v s . \mathrm{C}_{\mathrm{e}}\right)$, Type $2\left(1 / \mathrm{q}_{\mathrm{e}} v s .1 / \mathrm{C}_{\mathrm{e}}\right)$, Type $3\left(\mathrm{q}_{\mathrm{e}}\right.$ vs. $\left.\mathrm{q}_{\mathrm{e}} / \mathrm{C}_{\mathrm{e}}\right)$, and Type $4\left(\mathrm{q}_{\mathrm{e}} / \mathrm{C}_{\mathrm{e}}\right.$ vs. $\left.\mathrm{q}_{\mathrm{e}}\right)$. 

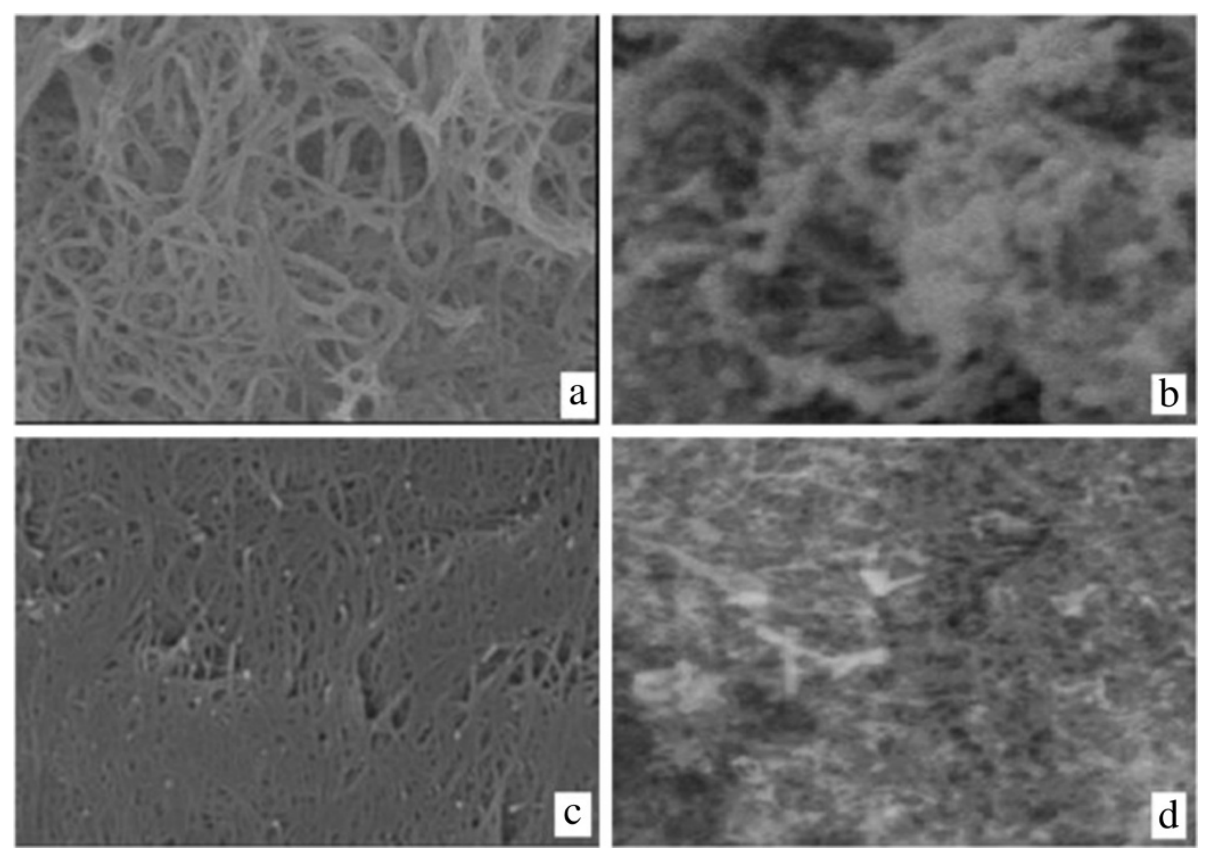

Figure 3 SEM images of SWCNT-COOH (a) before adsorption, (b) after adsorption, and SWCNTs (c) before adsorption, (d) after adsorption.

respectively [34-36]. The essential characteristics of the Langmuir isotherm can be expressed in terms of a dimensionless equilibrium parameter $\left(\mathrm{R}_{\mathrm{L}}\right)$ which can be defined by:

$$
\mathrm{R}_{\mathrm{L}}=\frac{1}{1+\mathrm{KCO}}
$$

The $R_{L}$ value indicates the type of the isotherm to be either irreversible $\left(R_{L}=0\right)$, favorable $\left(0<R_{L}<1\right)$, linear $\left(R_{L}=1\right)$ or unfavorable $\left(R_{L}>1\right)$ [37]. Figures 1 and 2 shows

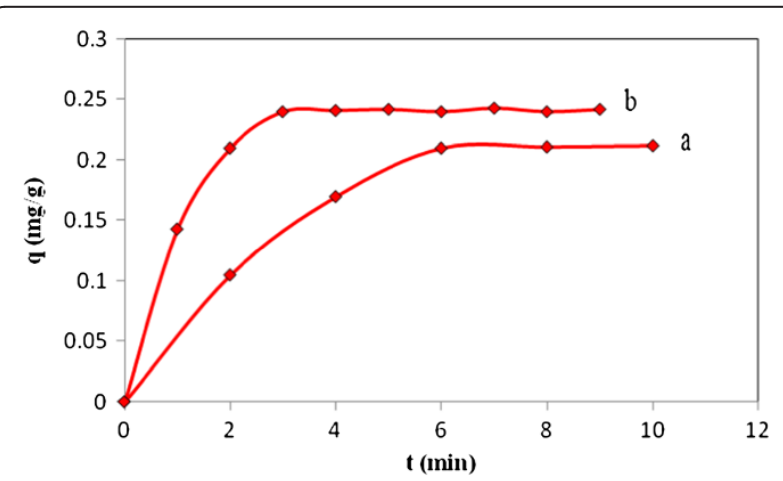

Figure 4 Effect of contact time on the adsorption of EtBr with (a) SWCNTs and (b) SWCNT-COOH, initial concentration, $20 \mathrm{ml}$, $30 \mathrm{mg} / \mathrm{L}$; adsorbent dosage, $20 \mathrm{mg}$ and $\mathrm{T}=298 \pm 1 \mathrm{~K}$. the adsorption isotherm Langmuir of EtBr on SWCNTs and SWCNT-COOH surfaces, respectively.

The Freundlich model assumes a heterogeneous adsorption surface with sites that have different energies of adsorption and are not equally available [38-40]. The Freundlich isotherm is more widely used but provides no information on the monolayer adsorption capacity, in contrast to the Langmuir model. Its linearized form can be written as:

$$
\ln \mathrm{q}_{\mathrm{e}}=\ln K_{\mathrm{F}}+1 / \mathrm{n} \quad \ln \mathrm{C}_{\mathrm{e}}
$$

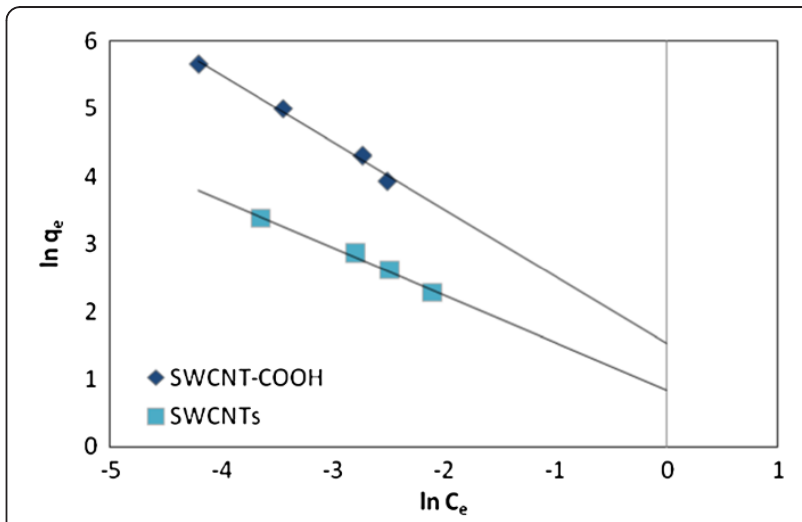

Figure 5 Freundlich adsorption isotherm of EtBr on SWCNTs and SWCNT-COOH surface. 
Table 1 Langmuir isotherm parameters and ARE parameter for EtBr by SWCNTs surface

\begin{tabular}{|c|c|c|c|c|c|c|}
\hline Type & Equation & $Q_{m}(m g / g)$ & $\mathrm{K}(\mathrm{L} / \mathrm{mg})$ & $\mathrm{R}^{2}$ & $\mathrm{R}_{\mathrm{L}}$ & ARE \\
\hline Type 1 & $\mathrm{Ce} / \mathrm{qe}=1 / \mathrm{KQ}_{\mathrm{m}}+\mathrm{Ce} / \mathrm{Q}_{\mathrm{m}}$ & 0.770 & 4.672 & 0.9964 & $0.3-0.6$ & 0.075 \\
\hline Type 2 & $1 / \mathrm{qe}=1 / \mathrm{Q}_{\mathrm{m}}+1 / \mathrm{KQ}_{\mathrm{m}} \mathrm{Ce}$ & 0.750 & 4.555 & 0.9994 & & \\
\hline Type 3 & $\mathrm{qe}=\mathrm{Q}_{\mathrm{m}}-\mathrm{qe} / \mathrm{KCe}$ & 0.802 & 4.032 & 0.9913 & & \\
\hline Type 4 & $\mathrm{qe} / \mathrm{Ce}=\mathrm{KQ}_{\mathrm{m}}-\mathrm{Kqe}$ & 0.808 & 4.085 & 0.9925 & & \\
\hline
\end{tabular}

where $K_{F}(1 / m g)$ and $n$ (dimensionless) are the Freundlich adsorption isotherm constants, being indicative of the extent of adsorption and the degree of nonlinearity between solution concentration and adsorption, respectively.

Temkin isotherm [41] describes the behavior of adsorption systems on a heterogeneous surface, and the linear form of Temkin isotherm is expressed as:

$$
q_{e}=\beta \ln K_{T}+\beta \ln C_{e}
$$

The adsorption data were analyzed according to Eq. (6). $\mathrm{K}_{\mathrm{T}}$ is the equilibrium binding constant $(\mathrm{L} / \mathrm{mg})$ corresponding to the maximum binding energy and constant $b=R T / \beta$ $(\mathrm{KJ} / \mathrm{mol})$ is related to the heat of adsorption.

Redlich and Peterson [42] incorporate three parameters into an empirical isotherm. The Redliche Peterson isotherm has a linear dependence on concentration in the numerator and an exponential function in the denominator. It approaches the Freundlich isotherm at high concentration and is in accordance with the low concentration limit of the Langmuir equation. Furthermore, the R-P equation incorporates three parameters into an empirical isotherm and, therefore, can be applied either in homogenous or heterogeneous systems due to the high versatility of the equation. It can be described as follows:

$$
q_{e}=\frac{K_{R} C_{e}}{1+a_{R} C_{e}^{\beta}}
$$

where $K_{R}$ is $R-P$ isotherm constant $(L / g)$, $a_{R}$ is $R-P$ isotherm constant $(1 / \mathrm{mg})$ and $\beta$ is the exponent which lies between 1 and 0 . That is, the Henry's Law equation. Eq. 7 can be converting to a linear form by taking logarithms:

$$
\ln \left(K_{\mathrm{R}} \frac{\mathrm{C}_{\mathrm{e}}}{\mathrm{q}_{\mathrm{e}}}-1\right)=\ln \mathrm{a}_{\mathrm{R}}+\beta \ln \mathrm{C}_{\mathrm{e}}
$$

Therefore a minimization procedure is adopted to maximize the coefficient of determination, between the theoretical data for predicted from the linearized form of Redlich-Peterson isotherm equation and the experimental data.

\section{Kinetics study}

\section{Pseudo first-order kinetics}

The pseudo first-order equation (Lagergren's equation) describes adsorption in solid-liquid systems based on the sorption capacity of solids [43]. The linear form of pseudo first-order model can be expressed as:

$$
\log \left(q_{e}-q\right)=\log \left(q_{e}\right)-k_{1} t
$$

where $\mathrm{q}_{\mathrm{e}}(\mathrm{mg} / \mathrm{g})$ and $\mathrm{q}$ are the amount each of $\mathrm{EtBr}$ adsorbed on the adsorbents at equilibrium and at various times $t$ and $k_{1}$ is the rate constant of the pseudo first-order model for the adsorption $(1 / \mathrm{min})$ [43].

\section{Pseudo second-order kinetics}

The pseudo second-order rate expression, which has been applied for analyzing chemisorption kinetics from liquid solutions [44], is linearly expressed as:

$$
t / q=1 / k_{2} q_{e}^{2}+\mathrm{t} / q_{e}
$$

where $\mathrm{q}_{\mathrm{e}}$ and $\mathrm{q}$ are defined as in the pseudo first-order model and $k_{2}$ is the rate constant of the pseudo secondorder model for adsorption ( $\mathrm{g} / \mathrm{mg} \mathrm{min})$ [45].

\section{Results}

\section{Characterization of carbon nanotubes}

Figure 3 show the scanning electron microscopy images (SEM) of the carbon nanotubes. As seen in Figure 3 is

\begin{tabular}{|c|c|c|c|c|c|c|}
\hline Type & Equation & $Q_{m}(m g / g)$ & $\mathrm{K}(\mathrm{L} / \mathrm{mg})$ & $\mathrm{R}^{2}$ & $\mathbf{R}_{\mathbf{L}}$ & ARE \\
\hline Type 1 & $\mathrm{Ce} / \mathrm{qe}=1 / \mathrm{KQ}_{\mathrm{m}}+\mathrm{Ce} / \mathrm{Q}_{\mathrm{m}}$ & 0.830 & 7.751 & 0.9954 & $0.2-0.5$ & 0.05 \\
\hline Type 2 & $1 / \mathrm{qe}=1 / \mathrm{Q}_{\mathrm{m}}+1 / \mathrm{KQ}_{\mathrm{m}} \mathrm{Ce}$ & 0.844 & 7.601 & 0.9958 & & \\
\hline Type 3 & $\mathrm{qe}=\mathrm{Q}_{\mathrm{m}}-\mathrm{qe} / \mathrm{KCe}$ & 0.834 & 7.633 & 0.9927 & & \\
\hline Type 4 & $\mathrm{qe} / \mathrm{Ce}=\mathrm{KQ}_{\mathrm{m}}-\mathrm{Kqe}$ & 0.840 & 7.553 & 0.9919 & & \\
\hline
\end{tabular}
carboxylate group functionalized single-walled carbon nanotube having a negative surface charge and porosity much more than single-walled carbon nanotube. Based

Table 2 Langmuir isotherm parameters and ARE parameter for EtBr by SWCNT-COOH surface 
Table 3 Freundlich, Temkin and Redlich-Peterson isotherm parameters for removal EtBr by SWCNT-COOH and SWCNTs surface

\begin{tabular}{lccccc}
\hline Freundlich & $\mathbf{K}_{\mathbf{F}}(\mathbf{m g} / \mathbf{g})$ & $\mathbf{n}$ & $\mathbf{R}^{\mathbf{2}}$ & ARE \\
\hline SWCNT-COOH & 4.6089 & 1.006 & 0.9903 & 0.1 \\
\hline SWCNTs & 2.3189 & 1.419 & 0.9904 & 0.1 \\
\hline Temkin & $\mathrm{K}_{\mathrm{T}}(\mathrm{L} / \mathrm{g})$ & $\beta(\mathrm{mg} / \mathrm{L})$ & $\mathrm{b}(\mathrm{K} / \mathrm{mol})$ & $\mathrm{R}^{2}$ & ARE \\
\hline SWCNT-COOH & 126.97 & 0.1235 & 20.061 & 0.9894 & 0.4 \\
\hline SWCNTs & 45.150 & 0.1608 & 15.407 & 0.9882 & 0.4 \\
\hline Redlich-Peterson & $a_{R}(\mathrm{l} / \mathrm{mg})$ & $\mathrm{K}_{\mathrm{R}}(\mathrm{L} / \mathrm{g})$ & $\beta$ & $\mathrm{R}^{2}$ & ARE \\
\hline SWCNT-COOH & 0.9546 & 11.286 & 0.0705 & 0.9728 & 0.55 \\
\hline SWCNTS & 0.4885 & 4.467 & 0.0944 & 0.9732 & 0.54 \\
\hline
\end{tabular}

on these textural characteristics explained above it is expected that SWCNT-COOH would present higher sorption capacity than the SWCNTs for the EtBr adsorption, besides of presenting a faster kinetic.

\section{Effect of contact time}

Effect of contact time on EtBr adsorption by SWCNT$\mathrm{COOH}$ and SWCNTs were studied by variation of the contact time (0 to $10 \mathrm{~min})$ for constant initial concentrations $(30 \mathrm{mg} / \mathrm{L})$. Figure 4 shows the effect of contact time on the adsorption of EtBr on to (a) SWCNTs and (b) SWCNT-COOH.

\section{Effect of EtBr initial concentration}

In the present study, the adsorption experiments are performed to study the effect of $\mathrm{EtBr}$ initial concentration by varying it from 10 to $40 \mathrm{mg} / \mathrm{L}$, while maintaining the SWCNT-COOH and SWCNTs amount $0.02 \mathrm{~g} / \mathrm{L}$.

\section{Effect of temperature on the adsorption}

Figure 2 shows the representative plots of adsorption amount of EtBr onto SWCNT-COOH and SWCNTs

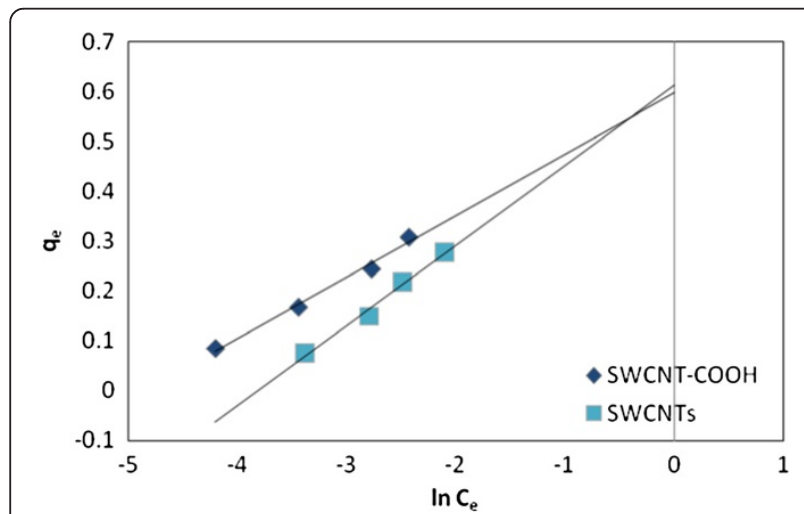

Figure 6 Temkin adsorption isotherm of EtBr on SWCNTs and SWCNT-COOH surface.

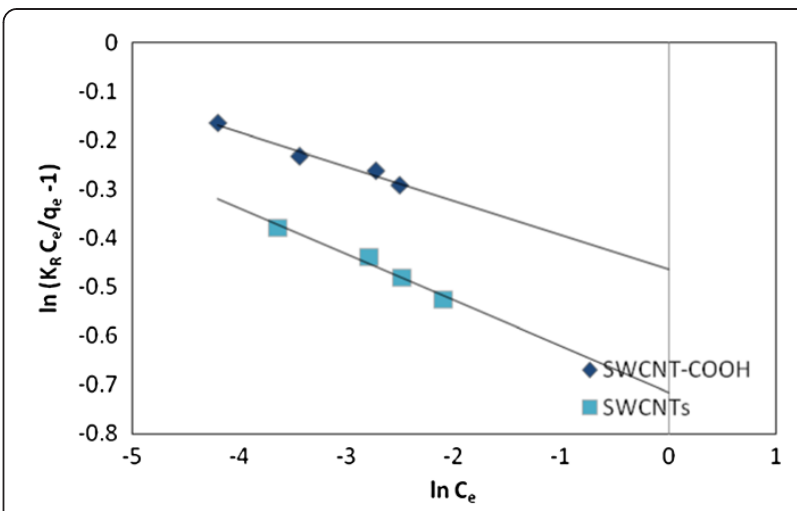

Figure 7 Redlich-Peterson adsorption isotherm of EtBr on SWCNTs and SWCNT-COOH surface.

versus different temperature ranging from 298 to $328^{\circ} \mathrm{K}$. In this section, concentration of EtBr was $30 \mathrm{mg} / \mathrm{L}$ and contacts time were 3 and 6 min for SWCNT-COOH and SWCNTs, respectively. It was found that the adsorption capacity of EtBr onto carbon nanotubes was found to increase with a rise in temperature.

\section{Equilibrium}

Figure 5 shows the adsorption isotherm Freundlich of $\mathrm{EtBr}$ on SWCNT-COOH and SWCNTs surfaces, respectively. Tables 1, 2 and 3 summarize the coefficients of Langmuir, and Freundlich isotherms for adsorbents, respectively. Figure 6 shows the effect of temperature on the adsorption of EtBr with (a) SWCNTs and (b) SWCNT-COOH. Figures 7 and 8 show the adsorption isotherm Temkin and Redlich-Peterson of $\mathrm{EtBr}$ on the adsorbents surfaces, respectively.

\section{Kinetics}

Figure 9 shows a plot of linearization form of pseudo first-order model. This Fig. shows a plot of linearization

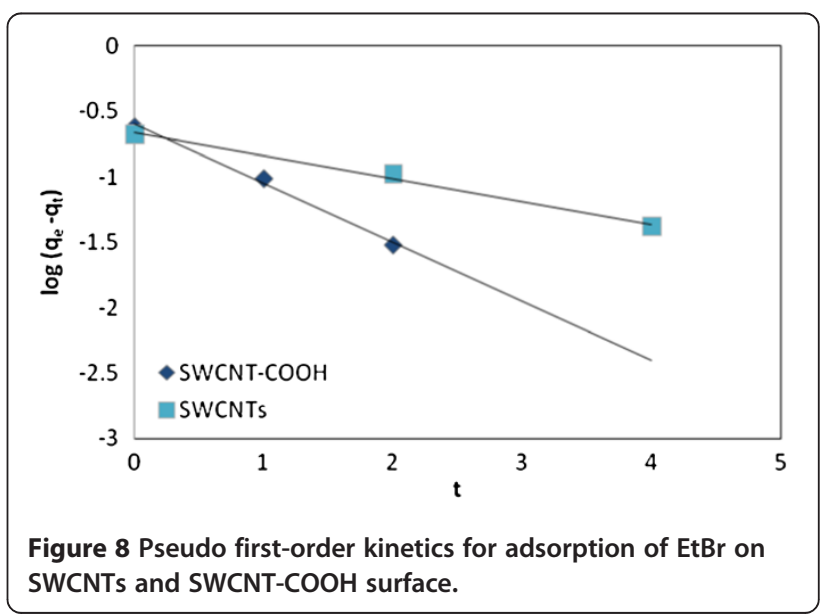




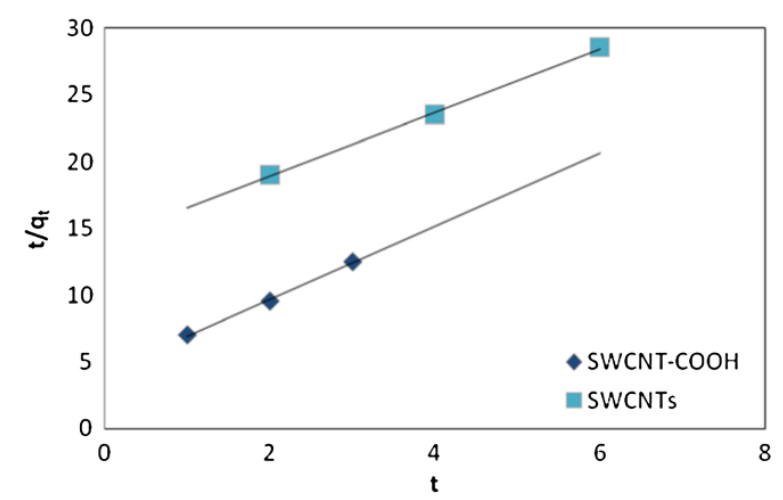

Figure 9 Pseudo second-order kinetics for adsorption of $\mathrm{EtBr}$ on SWCNTs and SWCNT-COOH surface.

form of pseudo second-order model at constant concentrations studied the results of are presented in Table 4.

\section{Discussion}

\section{Effect of contact time}

According to Figure 4, EtBr adsorption rate increased quickly with time and then reached equilibrium. SWCNT$\mathrm{COOH}$ and SWCNTs surfaces were treated by EtBr solutions $(30 \mathrm{mg} / \mathrm{L}$ and $\mathrm{T}=298 \pm 1 \mathrm{~K}$ ) in order to optimize contact time respect to EtBr. The amounts of adsorbed ion on the adsorbents were analyzed using UV-visible Spectrophotometer.

\section{Effect of temperature}

According to Figure 1; the adsorption capacity of EtBr onto carbon nanotubes was found to increase with a rise in temperature, suggesting the process in this research has been endothermic [44]. An increase in the amount of equilibrium adsorption of each ion with the rise in temperature may be explained by fact that the adsorbent sites were more active at higher temperatures.

\section{Adsorption isotherms}

According to Figure 2 the constants of Langmuir models is obtained from fitting the adsorption equilibrium data and is listed in Tables 1 and 2. A comparison of the $R^{2}$ and ARE values given in Tables 1 and 2 with 2 indicates that Langmuir isotherm better fits the experimental data than does the other isotherms. The validity of Langmuir isotherm suggests that adsorption is a monolayer process, and adsorption of all species requires equal activation energy. Moreover, $\mathrm{K}$ values for various adsorbents followed the order SWCNT-COOH $>$ SWCNTs, suggesting that the affinity of the binding sites for each ion also followed this order. The $\mathrm{R}_{\mathrm{L}}$ parameter lies between 0.22 and 0.60 which proves that the adsorption process is favorable and SWCNTs and SWCNT-COOH are potential adsorbents for the removal of EtBr from drinking water.

\section{Adsorption Kinetics}

The high correlations coefficient and high agreement that exist between the calculated and experimental $q_{\mathrm{e}}$ values of the pseudo second-order kinetic model over the other model renders it best in adsorption of EtBr. This confirms that the sorption data for removal of $\mathrm{EtBr}$ on SWCNTs and SWCNT-COOH are well represented by the pseudo-second-order kinetics for the entire sorption period.

\section{Reusability}

Repeated usage of CNT filters is one of the critical considerations in a treatment plant from economics standpoint. CNT filters are reusable as evidenced by Brady-Estevez et al. (2008) and Srivatsava et al. (2004). On the other hand CNT filters, due to their excellent mechanical properties prevent such deformational changes. Moreover, CNT filters support simple thermal regeneration techniques, whereas with polymeric membranes it is not possible $[46,47]$.

\section{Conclusion}

This investigation examined the equilibrium and the dynamic adsorption of EtBr on SWCNT-COOH and SWCNTs surfaces. The adsorption capacity was highest when $20 \mathrm{mg} / \mathrm{SWCNT}-\mathrm{COOH}$ and SWCNTs were added. The results suggested that the adsorption of $\mathrm{EtBr}$ on SWCNT-COOH and SWCNTs surfaces increased with temperature. The adsorption of mentioned ions on SWCNT$\mathrm{COOH}$ is more than SWCNTs surfaces. SWCNT-COOH and SWCNTs are after adsorption can be recycle and usable. In addition, SWCNT-COOH and SWCNTs are adsorbents have desorption capabilities.

Table 4 Comparison of the pseudo first- and second-order rate constants

\begin{tabular}{|c|c|c|c|c|c|c|c|c|}
\hline & \multicolumn{4}{|c|}{ Pseudo first-order } & \multicolumn{4}{|c|}{ Pseudo second-order } \\
\hline & $\mathrm{k}_{1}$ & $\mathrm{q}_{\mathrm{e}}$ & $R^{2}$ & ARE & $\mathrm{k}_{2}$ & $\mathrm{q}_{\mathrm{e}}$ & $R^{2}$ & ARE \\
\hline & (1/min) & $(\mathrm{mg} / \mathrm{g})$ & & & (g/mg min) & $(\mathrm{mg} / \mathrm{g})$ & & \\
\hline SWCNT-COOH & 0.1755 & 0.281 & 0.9946 & 0.2 & 7.6335 & 0.266 & 0.9978 & 0.1 \\
\hline SWCNTS & 0.4515 & 0.238 & 0.9933 & 0.2 & 5.7142 & 0.230 & 0.9988 & 0.1 \\
\hline
\end{tabular}




\section{Competing interests}

The authors declare that they have no competing interests.

\section{Authors' contributions}

MN and KN carried out the mechanism of adsorption studies and participated in the drafted the manuscript. OM and AF carried out the isotherms and kinetics of adsorption studies and the effect of different parameters studies. All authors read and approved the final manuscript.

\section{Acknowledgements}

This study was conducted in the Department of Chemistry, Shahr-e-Qods Branch and was financially supported by Islamic Azad University.

\section{Author details}

'Department of Chemistry, Shahre-Qods Branch, Islamic Azad University, Tehran, Iran. ${ }^{2}$ Department of Virology, School of Genetics, School of Public Health, Tehran University of Medical Sciences, Tehran, Iran. ${ }^{3}$ Department of Environmental Health Engineering, School of Public Health and Center for Air Quality Research, Institute for Environmental Research, Tehran University of Medical Sciences, Tehran, Iran.

Received: 5 November 2013 Accepted: 10 November 2013

Published: 8 January 2014

\section{References}

1. Kikuchi $\mathrm{H}$ : The investigation about the nature measurement result of 1999 groundwater quality and a groundwater-contamination example. Water Waste 2001, 43:396.

2. Dobaradaran S, Nabizadeh R, Mahvi AH, Mesdaghinia AR, Naddafi $K$, Yunesian M, Rastkari N, Nazmara S: Survey on degradation rates of trichloroethylene in aqueous solutions by ultrasound. Iran J Environ Health Sci 2010, 7:307.

3. Nakano Y, Li QH, Nishijima W, Shoto E, Okada M: Biodegradation of trichloroethylene (tce) adsorbed on granular activated carbon (gac). Water Res 2000, 34:4139.

4. Stenzel MH: Remove organics by activated carbon adsorption. ChemEng Prog 1993, 89:36.

5. Golden TC, Sircar S: Gas adsorption on Silicalite. J Colloid Interface Sci 1994, 162:182e8.

6. Yun JH, Hwang KY, Choi DK: Adsorption of benzene and toluene vapors on activated carbon fiber at 298, 323, and 348 K. J Chem Eng Data 1998 43:843e5.

7. Annadurai $G$, Juang RS, Lee DJ: Use of cellulose-based wastes for adsorption of dyes from aqueous solutions. J Hazard Mater 2002, 92:263.

8. Ni ZM, Xia SJ, Wang LG, Xing FF, Pan GX: Treatment of methyl orange by calcined layered double hydroxides in aqueous solution: adsorption property and kinetic studies. J Colloid Interface Sci 2007, 316:284.

9. Huang JH, Huang KL, Liu SQ, Wang AT, Yan C: Adsorption of Rhodamine B and methyl orange on a hypercrosslinked polymeric adsorbent in aqueous solution. Colloids Surf A: Physicochem Eng Aspects 2008, 330:55.

10. Samarghandi M, Hadi M, Moayedi S, Askari F: Two-parameter isotherms of methyl orange sorption by pinecone derived activated carbon. Iran J Environ Health Sci Eng 2009, 6:285.

11. lijima S: Helical microtubules of graphitic carbon. Nature 1991, 354:56.

12. MortezaAli A, Sani S: Study of growth parameters on structural properties of $\mathrm{TiO}_{2}$ nanowires. J Nanostruct Chem 2013, 3:35.

13. Shokrieh MM, Saeedi A, Chitsazzadeh M: Mechanical properties of multi-walled carbon nanotube/polyester nanocomposites. J Nanostruct Chem 2013, 3:20

14. Banerji B, Pramanik SK, Pal U, Maiti NC: Dipeptide derived from Benzylcystine forms unbranched Nanotubes in aqueous solution. J Nanostruct Chem 2013, 3:12.

15. Wang M, Pramoda KP, Goh SH: Enhancement of the mechanical properties of poly (styrene-co-Acrylonitrile) with poly(methyl Methacrylate)-grafted multiwalled carbon nanotubes. Polymer 2005, 46:11510.

16. Tadjarodi A, Imani M, Kerdari H: Adsorption kinetics, thermodynamic studies, and high performance of $\mathrm{CdO}$ cauliflower-like nanostructure on the removal of Congo red from aqueous solution. J Nanostruct Chem 2013, 3:51.
17. Mauter MS, Elimelech M: Environmental applications of carbon-based nanomaterials. Environ Sci Technol 2008, 42:5843.

18. Hierold C, Jungen A, Stampfer C, Helbling T: Nano electromechanical sensors based on carbon nanotubes. Sensors Actuators A Phys 2007, 136:51.

19. Fujiwara A, Ishii K, Suematsu H, Kataura H, Maniwa Y, Suzuki S: Gas adsorption in the inside and outside of single-walled carbon nanotubes. ChemPhysLett 2001, 336:205.

20. Romo-Herrera JM, Terrones M, Terrones H, Meunier V: Guiding electrical current in nanotube circuits using structural defects, a step forward in nanoelectronics. ACS Nano 2008, 2:2585.

21. Najafi F: Investigation of a QM/MM study on interaction of a carbon nanotube with cytarabine drug in various solvents and temperatures. J Nanostruct Chem 2013, 3:23.

22. Salam MA, Burk RC: Thermodynamics of pentachlorophenol adsorption from aqueous solutions by oxidized multi-walled carbon nanotubes. Applied Surface Sci 1975, 2008:255.

23. Sua F, Lu C, Hu S: Adsorption of benzene, toluene, Ethylbenzene and p-xylene By $\mathrm{NaOCl}$-oxidized carbon nanotubes. Colloids Surf $\mathrm{A}$ : Physicochem Eng Aspects 2010, 353:83.

24. Chin CJM, Shih LC, Tsai HJ, Liu TK: Adsorption of o-xylene and p-xylenefrom water by SWCNTs. Carbon 2007, 45:1254.

25. Schierz A, Zanker H: Aqueous suspensions of carbon nanotubes: Surface oxidation, colloidal stability and uranium sorption. Envi Pollution 2009, 157:1088.

26. Hu J, Chen C, Zhu X, Wang X: Removal of chromium from aqueous solution by using oxidized multi-walled carbon nanotubes. $J$ Hazard Mater 2009, 162:1542.

27. Ruparelia JP, Duttagupta SP, Chatterjee AK, Mukherji S: Potential of carbon nanomaterials for removal of heavy metals from water. Desalination 2008, 232:145.

28. Demirbasa E, Dizge N, Sulak MT, Kobya M: Adsorption kinetics and equilibrium of copper from aqueous solutions using hazelnut shell activated carbon. Chemical Engineering J 2009, 148:480.

29. Wang H, Zhou A, Peng F, Yu H, Yang J: Mechanism study on adsorption of acidified multi-walled carbon nanotubes to $\mathrm{Pb}$ (II). J Colloid Interface Sci 2007, 316:277

30. Safavi A, Maleki N, Doroodmand MM: Fabrication of a selective mercury sensor based on the adsorption of cold vapor of mercury on carbon nanotubes: Determination of mercury in industrial wastewater. J Hazardous Materials 2010, 173:622.

31. Vukovic'a GD, Marinkovic'a AD, Ristic'a MD, Aleksic'a R, Perić-Grujić AA, C olic'b M: Removal of cadmium from aqueous solutions by oxidized and ethylenediamine-functionalized multi-walled carbon nanotubes. Chemical Engineering J 2010, 157:238.

32. Li Y, Wang S, Luan Z, Ding J, Xu C: Adsorption of cadmium(II) from aqueous solution by surface oxidized carbon nanotubes. Carbon 2003, 41:1057.

33. Moradi O, Zare $\mathrm{K}$ : Adsorption of $\mathrm{Pb}$ (II), $\mathrm{Cd}$ (II) and $\mathrm{Cu}(\mathrm{II})$ lons in Aqueous Solution on SWCNTs and SWCNT -COOH Surfaces: Kinetics Studies, Fullerenes. Nanotubes Carbon Nanostruct 2010, 19:628.

34. Karimi L, Zohoori S: Superior photocatalytic degradation of azo dyes in aqueous solutions using $\mathrm{TiO}_{2} / \mathrm{SrTiO}_{3}$ nanocomposite. J Nanostruct Chem 2013, 3:32

35. Lu C, Chiu H: Adsorption of zinc (II) from water with purified carbon nanotubes. Chem Eng Sci 2006, 61:1138.

36. Hu Y, Li I, Ding J, Luan Z, Di Z, Zhu Y, Xu C, Wu D, Wei B: Competitive adsorption of $\mathrm{Pb}^{2+}, \mathrm{Cu}^{2+}$ and $\mathrm{Cd}^{2+}$ ions from aqueous solutions by multi-walled carbon nanotubes. Carbon 2003, 41:2787.

37. Webber TW, Chakkravorti RK: Pore and solid diffusion models for fixed-bed adsorbers. AlChE J 1974, 20:228.

38. Ayad MM, El-Nasr A: Anionic dye (acid green 25) adsorption from water by using polyaniline nanotubes salt/silica composite. J Nanostruct Chem 2012, 3:3.

39. Rao MM, Ramesh A, Rao GPC, Seshaiah K: Removal of copper and cadmium from the aqueous solutions by activated carbon derived from Ceibapentandrahulls. J Hazard Mater B 2006, 129:123.

40. Bulut Y, Gozubenli N, Aydın H: Equilibrium and kinetics studies for adsorption of direct blue 71 from aqueous solution by wheat shells. J Hazard Mater 2007, 144:300.

41. Olgun A, Atar N: Equilibrium and kinetic adsorption study of basic Yellow 28 and Basic Red 46 by a boron industry waste. J Hazardous Mater 2009, 161:148. 
42. Redlich O, Peterson DL: A useful adsorption isotherm. J Phys Chem 1959, 63:1024.

43. Ho YS, McKay G: Sorption of dye from aqueous solution by pit. Chem Eng J 1998, 70:115.

44. Niu JJ, Wang JN: Effect of temperature on chemical activation of carbon nanotubes. Solid State Sci 2008, 10:1189.

45. Wang S, Zhu ZH: Effects of acidic treatment of activated carbons on dye adsorption. Dyes Pigments 2007, 75:306.

46. Brady-Estevez AS, Kang S, Elimelech M: A single walled carbon nanotube filter for removal of viral and bacterial pathogens. Small 2008, 4:481.

47. Srivatsava A, Srivatsava ON, Talapatra S, Vajtai R, Ajayan PM: Carbon nanotube filters. Nat Lett 2004, 3:610.

doi:10.1186/2052-336X-12-17

Cite this article as: Moradi et al:: Interaction of removal Ethidium

Bromide with Carbon Nanotube: Equilibrium and Isotherm studies.

Journal of Environmental Health Sciences \& Engineering 2014 12:17.

\section{Submit your next manuscript to BioMed Central and take full advantage of:}

- Convenient online submission

- Thorough peer review

- No space constraints or color figure charges

- Immediate publication on acceptance

- Inclusion in PubMed, CAS, Scopus and Google Scholar

- Research which is freely available for redistribution 